\title{
Conhecimento profissional para ensinar a explicar processos e fenômenos nas aulas de Química
}

\author{
Isauro Beltrán Núñez \\ Betania Leite Ramalho \\ Universidade Federal do Rio Grande do Norte
}

\section{Resumo}

A pesquisa, desenvolvida com estudantes de licenciatura em Química, identifica e caracteriza o conhecimento profissional dos licenciandos sobre a explicação científica e a importância dessa habilidade no ensino das ciências. $\bigcirc$ estudo tem caráter exploratório e fez uso de questionário como instrumento de pesquisa. Os resultados mostram que a maioria dos futuros professores associa a explicação científica à explicação didática, como referência ao ensino como transmissão e recuperação de informações, sem revelar sólidos conhecimentos de natureza epistemológica, coerentes com as discussões atuais da Didática das Ciências. Destaca-se a necessária inclusão dessa temática na formação inicial de professores de Ciências.

243 Palavras-chave: Linguagem científica. Explicação científica. Educação química.

\section{Professional knowledge to teach to explain processes and pheno- mena in classes of Chemistry}

\begin{abstract}
This research conducted with undergraduate students in Chemistry has identified and characterized the professional knowledge of undergraduates on the scientific explanation and the importance of this skill in Science Education. The study has an exploratory nature and used a questionnaire as a research tool. Results have shown that the majority of future teachers has associate the scientific explanation to the didactic explanation, as a reference to teaching as transmission and retrieval of information, without revealing solid knowledge of epistemological nature, consistent with the current discussions of Science Didactic. It is worth highlighting the necessary inclusion of this theme in the initial training of teachers of Science.
\end{abstract}

Keywords: Scientific language. Scientific explanation. Chemistry Education. 


\section{Conocimiento profesional para enseñar a explicar procesos y fenó- menos en las clases de química}

\section{Resumen}

La investigación realizada con estudiantes de licenciatura en Química, identifica y caracteriza el conocimiento professional de licenciandos sobre la explicación científica y la importância de esa habilidade en la enseñanza de las ciencias. El estúdio tiene carácter exploratório y uso el cuestionário como instrumento de investigación. Los resultados muestran que la mayoria de los futuros profesores relaciona la explicación con la transmisión y recuperación de informaciones, sin revelar sólidos conocimientos de naturaleza epistemológica, coherentes con las discusiones actuales de la Didáctica de la Ciencias. Se constata la necessária inclusión de esa temáica en la formación inicial de lo profesores de ciências.

Palabras-clave: Lenguaje cientifica. Explicación científica. Educación química.

\section{Introdução}

Nos Parâmetros Curriculares Nacionais (BRASIL, 2002), estão definidas, como competências básicas, a investigação, a compreensão, a interpretação e a utilização de modelos explicativos das diferentes ciências, em relação às habilidades de reconhecer, utilizar, interpretar e propor modelos explicativos para fenômenos ou sistemas naturais ou tecnológicos. Segundo Jimenéz (2003), as explicações constituem uma parte fundamental das aulas de ciências. O Projeto Pisa (Programa Internacional de Avaliação de Estudantes) confere importância à explicação de fenômenos científicos como parte da competência em ciências. Já no Enem (Exame Nacional do Ensino Médio), como aponta Núñez e Ramalho (201 1), a explicação é uma das habilidades gerais avaliadas nas provas da área de Ciências Naturais.

Não obstante, conforme Jimenez (2003), as explicações nas aulas de ciências não têm sido objeto da atenção necessária como parte das dificuldades de aprendizagem dos alunos. No ensino de ciências, especialmente, 
a forma de explicar, considerada um aspecto específico da comunicação, merece mais atenção e deve ser formada como habilidade.

Na Didática das Ciências Naturais, há um consenso entre os pesquisadores sobre a necessidade de que o seu ensino propicie aos estudantes condições para desenvolver habilidades cognitivo-linguísticas (argumentar, explicar, descrever). Isso se justifica por vários motivos como, por exemplo, promover melhor compreensão dos processos de produção do conhecimento científico, da natureza das ciências e da própria aprendizagem desses conteúdos.

Na opinião de Jimenéz (2003), a imagem que, em geral, as pessoas criam em relação às Ciências Naturais está diretamente associada aos experimentos. Embora seja certo que uma parte importante do trabalho científico seja de natureza experimental, o que pode levar à solução de problemas, é necessário considerar a importância que a linguagem e a comunicação têm nas Ciências Naturais e em seu ensino. Conforme Gomez-Moliné e Sanmartí (2000), a ciência tem-se desenvolvido, ao longo dos séculos, pela vontade das pessoas e de grupos interessados em explicar o mundo e seus fenômenos.

245 Ao falar e discutir entre eles, o conhecimento cientifico tem-se estruturado para ser transmitido às gerações seguintes. Lemke (1997) tem usado a expressão "falar ciências" para caracterizar a situação de aulas nas quais se produz uma verdadeira comunicação entre os alunos, discutem-se problemas entre eles, escreve-se sobre questões de ciências ou fazem-se perguntas.

As aulas de ciências são, também, espaços de comunicação onde se constroem significados por meio da linguagem. Pozo e Crespo (2009) referem-se aos procedimentos de exposição oral e escrita e ao desenvolvimento de capacidades para argumentar, explicar e justificar como alguns dos procedimentos para a aprendizagem das Ciências Naturais que, por seu caráter geral ou instrumental, não são ensinadas em sala de aula, questão que afeta (dificulta) a aprendizagem dos alunos. Para os autores, esses procedimentos são tão importantes como os próprios conhecimentos conceituais. Como explica Mortimer e Vieira (2010, p. 309): "[...] de um ponto de vista cognitivo, as atividades realizadas em sala de aula priorizam apenas a aquisição de conceitos e não uma interação entre alunos, ideias e linguagem." 
Aprender ciências, para Sanmartí (2007), supõe apropriar-se da linguagem da ciência, que leva a novas formas de ver, pensar e falar sobre os fatos e fenômenos da natureza, diferente das formas cotidianas de ver, pensar e falar tudo o que facilita o acesso à cultura científica. Para a autora, ensinar a falar e escrever ciências deve ser um dos objetivos prioritários das aulas de ciências para que os estudantes possam aceder a essa forma de conhecimento e a essa parte importante da cultura universal que é a ciência. Esse é um tipo de saber profissional que deve ser trabalhado com os professores e futuros professores de Ciências Naturais, relativos a ensinar a ensinar.

Diferentes estudos têm mostrado que os estudantes apresentam dificuldades para argumentar, explicar, descrever, em face de determinadas tarefas e situações que demandam essas habilidades cognitivo-linguísticas (CARVALHO, 2010; DUSCHL, 1998; NÚÑEZ; UHEARA, 20121. A escola, de forma geral, tem delegado a aprendizagem da linguagem à disciplina de Língua Portuguesa, desconsiderando o potencial e a importância da comunicação na aprendizagem das ciências e na compreensão da natureza do conhecimento científico. Os estudantes devem aprender a linguagem das ciências para compreender teorias, explicar processos e fenômenos, e desenvolver um pensamento científico como parte de sua educação científica.

No contexto da educação científica, diversos são os estudos sobre a explicação na escola. Não obstante, muitos desses estudos estão direcionados aos processos de como os estudantes aprendem a explicar, atribuindo menos ênfase ao modo como os professores aprendem a ensinar essa habilidade, o que inclui o conhecimento profissional dos professores.

Ogborn (1998) tem estudado o modo como os professores de ciências explicam ao estudar o significado semiótico das práticas, os objetivos e as atividades desses professores. Nesse sentido, direciona a atenção na explicitação didática, no ensino das ciências. Nos estudos conduzidos por Cornell e Yera (200 1), foram destacadas as dificuldades de estudantes dos últimos anos do ensino fundamental, na construção de explicações causais nas aulas de ciências, como resultado de um ensino fragmentado que desarticula os conhecimentos necessários à habilidade de explicar. No mesmo sentido, Núñez e Ramalho (2012) atribuem à pouca explicitação das ações que se devem realizar no processo de explicar, algumas das dificuldades dos estudantes para 
Conhecimento profissional para ensinar a explicar processos e fenômenos nas aulas de Química

aprender e dos professores para ensinar a explicação como habilidade nas Ciências Naturais.

Lira (2014), com base em uma profunda revisão das pesquisas publicadas nos Anais dos Encontros Nacionais de Pesquisa em Ensino de Ciências (ENPECs), ocorridos de 1997 a 2007, de três revistas nacionais de grande circulação, dedicadas ao ensino das Ciências Naturais concluiu que, apesar da relevância da explicação para a ciência e seu ensino, esta ainda não é posta como um objeto importante das pesquisas na área de ensino das ciências. Segundo a autora, em pouco mais de dez anos, foram apenas vinte e um trabalhos sobre explicação como objeto de estudo nessa área.

Ogborn (1998) chama a atenção para o fato de a atividade de explicar não ter sido vista como algo que se ensine ou aprenda, sendo o ato de explicar menos estudado do que as ideias científicas, como objeto da explicação. Ensinar a ensinar como atividade profissional tem sido uma constante nas preocupações das pesquisas em Didática das Ciências Naturais. Nesse contexto, a formação inicial situa-se como um itinerário organizado pedagogicamente para desenvolver conhecimentos, habilidades, atitudes e 247 competências, necessárias para o início da atividade de ensino como profissão (RAMALHO; NÚÑEZ; GAUTHIER, 2004). Darling-Hammond (2001) diz que a aprendizagem dos alunos depende, principalmente, do que os professores conhecem e do que podem fazer.

A formação inicial deve oportunizar aos licenciandos em Química compreender bem o conteúdo que devem ensinar, de maneira diferente daquela que aprenderam como estudantes. A formação inicial deve contribuir para se aprender a ensinar. Embora Marcelo (2012) e Carrascosa, Alis, Furió, Guisasola (2008) considerem que se aprende a ensinar na prática profissional, a formação inicial prepara para o início do exercício do ensino como atividade profissional, no contexto do desenvolvimento profissional (RAMALHO; NÚÑ̃E; GAUTHIER, 2004). Contudo, como destacam Núñez e Uheara (2012), a formação inicial de professores nos cursos de licenciatura para ensinar ciências não toma como preocupação ensinar a ensinar habilidades de natureza comunicativa (NÚÑ̃EZ; RAMALHO, 2012). 


\section{A habilidade de explicar processos e fenômenos nas aulas de química}

O uso do termo explicar remete a um conjunto variado de significados, o que evidencia seu caráter polissêmico. Os variados significados estão ancorados em diversas perspectivas: filosóficas, epistemológicas, linguísticas, didáticas, entre outras. Este trabalho deteve-se nas explicações em Ciências Naturais, uma vez que pesquisou-se o conhecimento de futuros professores de Química sobre essa habilidade cognitivo-linguística para ensinar os alunos a explicar e não serem apenas consumidores de explicações prontas e disponibilizadas em livros didáticos, na aprendizagem dessa disciplina.

Explicar, para Duval (1999), é produzir razões para tornar um fenômeno compreensível. Para o autor, uma explicação científica implica, no geral, relacionar um fato observado em um dado nível de organização com outro nível de organização inferior, o que leva à mudança de escala. Por sua vez, Sanmartí (2003) considera que o texto explicativo se caracteriza por ordenar determinados fatos, segundo uma relação que, quase sempre, é de causa-efeito. Já para Jorba (2000), explicar é apresentar raciocínios ou argumentos, estabelecendo relações nas quais os fatos explicados ganham sentido e conduzem à modificação do estado do conhecimento.

Existem diversas tipologias da explicação (HEMPEL, 1965; LEINHARDT, 1988). Mortimer e Vieira (2010), baseados em Charaudeau e Maingueneau (2004), distinguem a explicação como i) causal, ii) funcional e iii) intencional. Segundo Gilbert (1998), podem ser considerados cinco tipos de explicações, de acordo com a pergunta que se pretende responder:

a) explicação - descritiva. Como se comporta o fenômeno? É o tipo de explicação que fornece, apenas, um relato do comportamento do fenômeno após ser constatado pela via da atividade experimental;

explicação - intencional. Procura justificar a finalidade/relevância da investigação a ser desenvolvida pelos cientistas sobre o fenômeno em questão e responde à pergunta: Com que finalidade se investiga determinado fenômeno?; b) explicação - causal. Por que o fenômeno se comporta dessa e não de outra forma? Essa é a pergunta a que se responde nesse tipo de explicação, 
a qual se estrutura com base na relação de causalidade, ou seja, explica-se o mecanismo do fenômeno, estabelecendo uma relação de causa-efeito;

c) explicação - interpretativa. Diz respeito à resposta para a seguinte pergunta: Que entidades constituem o fenômeno? Centra-se na interpretação da estrutura Física do fenômeno, a partir da qual procura-se explicá-lo;

d) explicação - preditiva. Como se comportará o fenômeno caso venha a ser submetido a determinadas condições? É a pergunta que responde esse tipo de explicação, possibilitando uma resposta a partir de um dado conhecimento do comportamento do fenômeno, sob determinadas condições, sendo possível fazer uma previsão antecipada do que acontecerá em circunstâncias desconhecidas.

Explicação e aprendizagem das ciências estão estreitamente relacionadas, embora seus vínculos possam ser diferentes. Na sala de aula, a explicação envolve diferentes estratégias de comunicação, diferentes interesses, necessidades e motivações dos estudantes e do professor. Assim, explicar, nas aulas de ciências, não significa a reprodução de uma "explicação-pacote", disponível no livro didático ou fornecido por professores e colegas mais expe249 rientes, visto que se trata de um processo cognitivo-afetivo que mobiliza, de forma dinâmica, o saber científico a ser apropriado pelos estudantes para dar conta das razões que justificam a existência de um fenômeno ou processo da ciência, segundo um padrão específico de comunicação científica.

As formas de explicar nas aulas de ciências, analisadas sob o ponto de vista da teoria do discurso e da comunicação, têm mostrado as dificuldades dos professores para orientar e ensinar os alunos a usarem a linguagem na aprendizagem das ciências (LEMKE, 1997). Na sala de aula de Física, Química e Biologia, a explicação que os estudantes devem aprender é científica, e não só didática, ou seja, a explicação da explicação (EDER; ADÚRIZ-BRAVO, 2008).

Para Leinhardt (1987, p. 237), "[...] o coração de cada episódio do ensino é a explicação de uma ideia ou fenômeno independentemente do tipo de ensino, a construção de uma explicação é fundamental no processo de aprendizagem." Esse autor distingue, em Ciências, três tipos de explicações: a) a explicação baseada no campo disciplinar; b) a autoexplicação; c) a 
explicação para os estudantes (explicação didática). Essa última é o tipo de maior interesse para o trabalho do professor.

Como se tem explicitado, os processos docentes de aprender a ensinar/formar a habilidade para explicar têm sido pouco estudados de forma sistemática no contexto da área que se preocupa com os processos comunicativos nas salas de aula de Ciências Naturais, na formação de professores. Por isso, a importância de reiterar que a formação inicial dos professores que ensinam ciências, entre eles, os professores de Química, configura um espaço estratégico para se ensinar habilidades cognitivo-linguísticas, o que exige um conhecimento sólido e epistemológico da explicação na atividade das Ciências Naturais.

No estudo da Química como ciência no Ensino Médio, a explicação é uma habilidade essencial para se compreender os comportamentos, as propriedades das substâncias e dos materiais, assim como os porquês de as substâncias se transformarem em outras. As explicações permitem conferir sentidos aos conteúdos estudados ao relacioná-los com o cotidiano, a ciência, a tecnologia, a cultura e o mundo do trabalho. Tornar os estudantes sujeitos ativos na construção de explicações sob fortes motivações pode tornar as aulas de Química mais interessantes e com forte poder de contribuir, não só com a aprendizagem como também com o desenvolvimento integral dos estudantes (NÚÑ̃EZ, 2009).

Dessa forma, o conhecimento dos licenciandos sobre explicar como habilidade cognitivo-linguística e como procedimento das ciências torna-se relevante, uma vez que os docentes ensinam o que sabem, da forma como aprenderam, influenciando sua prática de ensino no início da atividade profissional. Ensinar os alunos a explicar novos fenômenos com base no conhecimento científico, ou até criar explicações, está relacionado com o conhecimento dos licenciandos sobre a natureza da ciência e as características essenciais do trabalho científico, já que existem muitas ideias distorcidas a respeito entre os professores que ensinam ciências.

objetivo geral desta pesquisa foi identificar e caracterizar o conhecimento profissional (saber disciplinar) de estudantes do curso de licenciatura em Química sobre explicação como habilidade cognitivo-linguística nas Ciências 
Naturais. Esse conhecimento poderá ajudar a repensar os processos de formação inicial de professores de Química.

A partir do objetivo geral, formularam-se as seguintes questões que nortearam o estudo:

a) Que importância os licenciandos atribuem à explicação científica nas Ciências Naturais?

b) Nas Ciências Naturais, o que é explicar para os licenciandos?

c) Na opinião dos licenciandos, a escola de Ensino Médio ensina os estudantes como se constroem explicações em Ciências Naturais?

d) E a formação inicial ensina como ensinar a explicar na aprendizagem das Ciências Naturais no contexto da escola?

\section{O contexto e os sujeitos da pesquisa}

A pesquisa foi desenvolvida em um curso de Licenciatura em Química da Universidade Federal do Rio Grande do Norte (UFRN), nas disciplinas de 251 Estágio e Práticas de Ensino de Química (EPEQ) II, III e IV. Na passagem pelos estágios, devem ser desenvolvidas estratégias e assimilados conhecimentos para o ensino da Química, uma vez que eles acontecem em diferentes períodos do curso da formação profissional. As quantidades de licenciandos por grupo foram: EPEQII: 35; EPEQIII: 40 e EPEQIV: 28, totalizando 103 participantes no estudo.

Do total dos licenciandos, $45 \%$ são do sexo feminino e $55 \%$, do masculino. Só 15\% têm alguma experiência na sala de aula como professor. É um grupo jovem, sendo a média da idade de 20,5 anos. $\bigcirc$ percentual de $75 \%$ fez Ensino Médio em escolas públicas. Esse padrão de comportamento é característico nos três grupos do estudo. Os estudantes de cada grupo (disciplina) foram convenientemente identificados, por meio de um código com a denominação da disciplina e uma letra (A, B, C, D, E, etc.), o que permitiu explicitar o conteúdo das categorias, usando fragmentos das respostas. 


\section{Metodologia da pesquisa}

A pesquisa tem caráter exploratório e procura aproximar-se de um problema pouco reportado na literatura especializada, no que diz respeito ao conhecimento profissional sobre explicação científica na Química, como ciência, e no seu ensino no contexto escolar, com professores durante o processo de sua formação inicial.

Considerando a natureza do objeto de estudo e o caráter da pesquisa, optou-se pelo questionário de perguntas de conteúdo, diretamente relacionadas com os objetivos da pesquisa, cujas respostas podem oferecer informações (ou falta delas) significativas. Nas perguntas abertas, não se limita ou preestabelece a forma de se responder e não se definem variantes de respostas. Portanto, se tem a liberdade para responder de acordo com a forma como é interpretada a questão.

questionário elaborado pelos pesquisadores foi validado por um especialista na temática e aplicado, inicialmente, a dez estudantes da licenciatura como pré-teste, com o objetivo de averiguar a clareza e a compreensão, o que possibilitou a elaboração da versão definitiva. A aplicação do questionário ocorreu de forma coletiva, em cada um dos grupos, nas salas de aula dos estudantes. Inicialmente, foi explicado aos licenciandos do que tratava a pesquisa e como deveriam responder ao questionário, assim como foi informado o tempo disponível para esse propósito.

As respostas dos licenciandos ao questionário foram tratadas pela técnica de Análise Temática de Conteúdo (BARDIN, 1977). Como explica Minayo (2010), os procedimentos da análise de conteúdo levam a relacionar estruturas semânticas (significantes) com estruturas sociológicas (significados) dos enunciados e articular a superfície dos enunciados dos textos com fatores que determinam suas características. Procurou-se, dessa forma, abranger e sumarizar dados, além de prover uma descrição primária, o que levou a suscitar novas preocupações, na medida em que as informações foram expostas de forma clara, permitindo uma aproximação à compreensão do objeto de estudo.

procedimento básico da análise de conteúdo é a definição de categorias pertencentes às respostas, para cada pergunta relacionada com os 
conhecimentos e as opiniões dos licenciandos sobre a explicação e seu ensino das Ciências Naturais. As categorias de natureza empírica foram construídas pelos três pesquisadores de forma separada e, posteriormente, negociadas para que fossem definidas as categorias por consenso, o que confere maior credibilidade ao estudo.

A análise foi amparada por procedimentos de cunho quantitativo e qualitativo de forma complementar segundo explicam Bogdan e Biklen (1994). Nesse sentido, os dados foram tratados por meio da técnica estatística de análise de frequência (dimensão quantitativa), organizados em tabelas, dando atenção às peculiaridades e às relações entre elementos, no que é significativo, relevante e ausente (dimensão qualitativa). As tabelas foram analisadas de forma a imprimir sentido aos dados e responder às questões de estudo.

\section{Resultados}

Estudar o conhecimento profissional de futuros professores na formação inicial sobre a explicação científica consiste na finalidade deste trabalho, no sentido de se poder contribuir com o ensinar a ensinar essa habilidade cognitivo-linguística na formação inicial dos professores de Química. Os resultados apresentados estão organizados segundo as questões que o estudo se propôs a responder no contexto dado.

A Tabela 1 mostra as categorias obtidas a partir das respostas dos licenciandos de cada grupo sobre a questão que procurava conhecer qual a importância da explicação para as Ciências Naturais. 
Tabela 1

Percentual de estudantes segundo a importância da explicação para as Ciências Naturais

\begin{tabular}{lcc|c}
\hline \multicolumn{1}{c|}{ Categorias } & EPEQll & EPEQlll & EPEQIV \\
\hline $\begin{array}{l}\text { Para a compreensão dos fenômenos e suas } \\
\text { transformações no ensino da Química }\end{array}$ & 22,4 & 40,0 & 36 \\
\hline $\begin{array}{l}\text { Para explicar aos estudantes as Ciências } \\
\text { Naturais, usando teorias e modelos }\end{array}$ & 18,4 & 37,5 & 34 \\
\hline Para saber o que se quer falar & 11,2 & 5,0 & 10 \\
\hline Para explicar os fenômenos & 2,8 & 5,0 & 5 \\
\hline Para expor as ideias & 11,2 & 5,0 & 5 \\
\hline Para passar informações & 34,0 & 5,0 & 10 \\
\hline $\begin{array}{l}\text { Para explicar sobre as ideias produzidas } \\
\text { pelos pesquisadores }\end{array}$ & 0 & 2,5 & 0 \\
\hline & 100 & 100 & 100 \\
\hline
\end{tabular}

Fonte | Dados da pesquisa

$\bigcirc$ conhecimento das epistemologias das ciências, dos processos de construção, da validação e da comunicação do conhecimento científico constitui um conhecimento relevante para a atividade de ensino do professor de Química. $\bigcirc$ primeiro ponto que chamou a atenção no resultado das questões foram as respostas com textos curtos, evidenciando limitações lexicais e semânticas ao discorrerem sobre a importância da explicação científica para as Ciências Naturais.

As respostas evidenciaram a falta de clareza epistemológica em relação ao papel da explicação nas Ciências Naturais. Isso pode estar atrelado às ideias dos professores na formação inicial sobre a ciência e sua produção, como têm apontado diversos estudos.

Como se observa na Tabela 1, os licenciandos dos três grupos, de forma geral, evidenciam as explicações didáticas para a compreensão dos fenômenos e as explicações didáticas na sala de aula em suas respostas, quando deveriam apresentar respostas baseadas em explicações científicas e 
suas diferentes modalidades. São exemplos dessa situação as respostas de três licenciandos de três grupos:

a) EIVC: A explicação é importante para ensinar os alunos de tal forma que compreendam os conteúdos que se ensinam, vinculados com a dia a dia, com o cotidiano (EIVC, 2014).

b) ElllA: Para as Ciências Naturais, a explicação é de muita importância, pois, através dela, é que são informados os conceitos científicos. A explicação possibilita a transmissão do conhecimento científico na sala de aula (EllIA, 2014). c) EllB: A explicação no ensino de Ciências Naturais é de extrema importância, visto que ajudará na compreensão dos conteúdos que estão sendo abordados. Conteúdos ininteligíveis não têm importância alguma (EllB, 2014).

Apesar de explicação e ensino estarem intimamente relacionados, um professor deve conhecer as diferenças das explicações científicas das explicações didáticas, como tem indicado Leinhardt (1988) e Gómez (2006). Como se observa na Tabela 1, existe um predomínio em relacionar a explicação com a compreensão dos fenômenos 22,4\%,40\% e 36\% respectivamente, bem como para $18,7 \%, 37,5 \%$ e 34\%, a explicação relaciona-se à utilização 255 de teorias e modelos com o fim de fazer o aluno compreender as Ciências Naturais. Ambas as categorias estão relacionadas com a explicação didática. Nesse sentido, a resposta de um licenciando do estágio IV é representativa:

a) EIVB: A importância da explicação para as Ciências Naturais é oportunizar, com base na explicação de algo, a compreensão do fenômeno por parte de todos, ou, pelo menos, da maioria dos estudantes das Ciências Naturais e, assim, havendo a compreensão, é possível explicá-la a outra pessoa (EIVB, 2014).

Chama atenção o fato de que, para 34\% dos licenciandos da turma II, a explicação diz respeito a passar informações. Existe uma preocupação com a compreensão do outro quando se explica. Não aparecem respostas que façam referências ao papel da explicação na produção do conhecimento científico como forma especial de comunicação, ou seja, relacionada com a discussão epistemológica da explicação científica na produção das Ciências Naturais. Esses resultados coincidem com os estudos de Eder e Aduriz-Bravo (2008), Sanmartí (2003), Lira (20 14) e Núñez e Ramalho (2012), nos quais evidenciam a explicação didática como preocupação dos professores. 
A explicação científica implica o uso e a construção da linguagem científica e, por isso, considera-se que a explicação está na gênese do conhecimento científico. Segundo Gilbert (1999), os cientistas não se conformam com descrições detalhadas, avançam no sentido de poder procurar responder o porquê de os fatos ocorrerem. $\bigcirc$ fato de não explicitarem características da linguagem científica e do léxico científico quando fazem referência à explicação científica, dificuldade estudada por Borsese e Esteban (2005), é uma outra ausência nas respostas dos licenciandos.

Na segunda questão de estudo, foi visível o interesse em conhecer o sentido que os licenciandos atribuem à explicação nas Ciências Naturais. Essa compreensão se torna relevante, pois, para ensinar ciências segundo as novas orientações da Didática das Ciências Naturais, os professores devem ter um profundo conhecimento sobre o que é explicar e como os cientistas constroem explicações como componente do conhecimento científico, uma vez que é possível considerar a explicação como uma das tarefas mais importantes das Ciências Naturais (EDER; ADÚRIZ-BRAVO, 2008). Isso se faz necessário para poder estruturar transposições didáticas no sentido de ensinar a explicar nas aulas de ciências.

Ensinar Química é, essencialmente, relacionar os níveis macroscópicos e microscópicos, usando modelos e teorias, processos nos quais a explicação científica exerce um papel relevante (IZQUIERDO, 2004). Explicar um fenômeno químico é uma forma de mostrar a compreensão deste como tem alertado Toulmin (1977). Assim, caso não haja clareza no sentido que as Ciências Naturais atribuem a essa habilidade cognitivo-linguística, não será possível ensinar, de forma adequada, o conteúdo das disciplinas científicas.

Ao analisar os percentuais das respostas, apresentados na Tabela 2, constatou-se que a maior parte situa-se novamente no campo semântico da explicação didática. Para um número expressivo dos licenciandos, explicar nas ciências é detalhar para que os outros compreendam ou entendam $167,8 \%$, $45 \%$ e $40 \%)$. 
Conhecimento profissional para ensinar a explicar processos e fenômenos nas aulas de Química

\section{Tabela 2}

Percentual de estudantes em relação ao que é explicar nas Ciências Naturais

\begin{tabular}{lcccc}
\hline \multicolumn{1}{c|}{ Categorias } & EPEQII & EPEQIII & EPEQIV \\
\hline Falar sobre algo & 3,6 & 7,5 & 5 \\
\hline Transmitir o que foi estudado por alguém & 7,2 & 12,5 & 25 \\
\hline $\begin{array}{l}\text { Detalhar algo de modo que outro } \\
\text { entenda }\end{array}$ & 67,8 & 45,0 & 40,0 \\
\hline Narrar com exatidão um fato & 7,2 & 2,5 & 8,0 \\
\hline $\begin{array}{l}\text { Descrever ou passar um conhecimento ou } \\
\text { informação }\end{array}$ & 7,0 & 10,0 & 12,5 \\
\hline $\begin{array}{l}\text { Mostrar de forma didática um conteúdo } \\
\text { Definir um fato ou uma teoria }\end{array}$ & 0 & 17,5 & 0 \\
\hline $\begin{array}{l}\text { Demonstrar os motivos e circunstâncias de } \\
\text { um fenômeno }\end{array}$ & 3,6 & 2,5 & 0 \\
\hline & 100 & 100 & 100 \\
\hline
\end{tabular}

Fonte | Dados da pesquisa

257 Os extratos abaixo exemplificam a compreensão dos licenciandos sobre o que é explicar nas ciências:

a) EllA No contexto das Ciências Naturais, explicar é mostrar, justificar, detaIhar algo de maneira que o outro compreenda como os fenômenos da natureza acontecem (EllA, 2014)

b) EllIB Nas Ciências Naturais, o contexto de explicar é detalhar algo de modo que o outro entenda algo, ou seja, facilitar a sua compreensão (EllIB, 20 14).

c) ENV Explicar é se mostrar como é um fenômeno, é poder, além de caracterizar, conseguir expor o que acontece com ele, suas particularidades, propriedades e conseguir assimilar as diferentes informações sobre o fenômeno (EIV, 2014 ).

Existe um percentual significativo nos três grupos, com destaque para o grupo II. Nesse grupo, os licenciandos reconhecem a explicação de maneira científica, como narrar, transmitir ou descrever um fenômeno. É o tipo de explicação característica, que Gilbert (1999) chama de descritiva, e que significa relatar o comportamento do fenômeno. A ideia de explicar como transmissão de conhecimento se faz presente para 7,2\%, 12,5\% e 25\% em cada grupo, respectivamente. É certo que a explicação se vincula com a compreensão e a tentativa de dar razões ao porquê dos fenômenos e processos em Química, 
usando modelos e a linguagem científica, questão que não aparece nas respostas dos licenciandos.

Constatou-se que a maioria dos licenciandos não expressam respostas que estabeleçam relações do tipo causa-efeito, relacionando os níveis macro e microscópicos, articulando fenômeno e essência como uma forma de se compreender o que é explicar nas Ciências Naturais. Como diz Sanmartí (2007), uma das maiores dificuldades dos estudantes nas aulas de Ciências é compreender (e praticar) e, para explicar fatos observáveis, deve-se fazer referências a entidades não observáveis, quer dizer, um modelo. Dessa forma, não fazem menção ao que é necessário para ensinar os estudantes a explicar os fenômenos e os processos nas aulas de Química.

Na terceira questão de estudo, busca-se conhecer se a escola do Ensino Médio oportuniza, aos estudantes, formas para desenvolver a habilidade de explicar nas Ciências Naturais.

\section{Tabela 3}

Percentual sobre a opinião de estudantes em relação à questão: "a escola ensina os estudantes como as Ciências Naturais constroem explicações, para saber explicar?"

\begin{tabular}{ccccc}
\hline Categorias & EPEQI & EPEQII & EPEQIII \\
\hline Sim & 0 & 2,5 & 3,6 \\
\hline Não & 100 & 95,0 & 82 \\
\hline Ass vezes & 0 & 2,5 & 14,4 \\
\hline Total & 100 & 100 & 100 \\
\hline
\end{tabular}

Fonte | Dados da pesquisa

Na Tabela 3, observa-se que, para 100\%, 95\% e 82\%, respectivamente, dos licenciandos participantes do estudo, a escola do Ensino Médio não ensina os processos usados pelas Ciências Naturais para construir explicações científicas, o que seria necessário para a compreensão dos conteúdos científicos que são estudados como parte da educação científica nas aulas de Química. 
Essas respostas são uma constatação empírica do fato de a escola não prestar atenção em ensinar a habilidade de explicar como procedimento fundamental para aprender Química. Essa situação é assinalada por Pozo e Crespo (2009), sendo que, para os autores, o conhecimento científico que a escola ensina é, sobretudo, o conhecimento conceitual desvinculado dos procedimentos necessários à atividade científica.

As respostas da solicitação feita aos licenciandos para justificativa do porquê de a escola não ensinar essa habilidade cognitivo-linguística estão apresentadas na Tabela 4.

\section{Tabela 4}

Percentual de estudantes segundo a justificativa do porquê de a escola não ensinar como as Ciências Naturais constroem as explicações científicas

\begin{tabular}{lcccc}
\hline \multicolumn{1}{c|}{ Categorias } & EPEQll & EPEQIII & EPEQIV \\
\hline $\begin{array}{l}\text { A escola transmite informações e fomenta a } \\
\text { memorização }\end{array}$ & 82 & 82,5 & 62,2 \\
\hline Os professores não sabem & 5,7 & 2,5 & 30,6 \\
\hline Faltam estímulos para os professores & 0 & 5,0 & 7,2 \\
\hline Não se explicam as razões & 12,3 & 10,0 & 0 \\
\hline \multicolumn{1}{c}{ Total } & 100 & 100 & 100 \\
\hline
\end{tabular}

Fonte | Dados da pesquisa

As porcentagens $82 \%, 82,5 \%$ e $62,2 \%$ apontam para a natureza transmissiva de informações e dos processos de memorizações basicamente usados no ensino dessa área do conhecimento, típico do chamado ensino tradicional, na opinião dos licenciandos. Essa situação pode ser ilustrada com as respostas de um estudante do estágio ll:

a) Ell-Em geral, nas escolas que tive contato, a ciência é tomada por um conjunto de informações, como uma coleção de explicações. Nesse ensino, não se discute o papel dos questionamentos e de como ou por que essas explicações são construídas. Não se ensina a ciência como uma forma de 
produção do conhecimento, mas como um conjunto de saberes consolidados e imutáveis (Ell, 2014).

As respostas confirmam diversos estudos que têm assinalado para a necessidade do estudo de ciências baseado na compreensão, e, também, para a importância de se superar a visão de ciência enquanto conhecimento comprovado por evidências experimentais, como um produto pronto, afastado da linguagem como ferramenta para pensar e "produzir ciência" (IZQUIERDO, 2005).

Tradicionalmente, a escola não tem prestado atenção aos processos de ensino e de aprendizagem de procedimentos, como a explicação em sala de aula, desconsiderando que estes devem ser entendidos, aprendidos e ensinados como parte dos conteúdos das Ciências (NÚÑ̃Z; RAMALHO, 2012). Geralmente, as explicações são fornecidas "prontas", como produto ou pacotes-modelos nos livros didáticos ou pelos professores, de forma tal que os estudantes passam a reproduzi-las de maneira acrítica e mecânica, desconhecendo a estrutura dessa atividade, fato evidenciado na resposta do licenciando do estágio IVA, a seguir reproduzida.

a) EIVA - A escola não está preocupada em ensinar aos alunos como se constroem as explicações nas ciências, há preocupação em "ensinar" o conteúdo didático e aprovar ou não os alunos. Acredito que os professores não possuem o conhecimento nesse assunto e, dessa maneira, não podem ensinar o que não sabem (EIVA, 2014)

A tabela 5 apresenta a resposta para a pergunta sobre se a formação inicial ensina como ensinar a explicar processos e fenômenos naturais nas aulas de Ciências Naturais. 


\section{Tabela 5}

Percentual de estudantes em relação a se a formação inicial ensina como ensinar a explicar nas aulas de Ciências Naturais

\begin{tabular}{lcccc}
\hline \multicolumn{1}{c|}{ Categorias } & EPEQII & EPEQIII & EPEQIV \\
\hline Sim & 0 & 17,5 & 34,2 \\
\hline Não & 100 & 72,5 & 62,2 \\
\hline Não responderam & 0 & 10,0 & 3,6 \\
\hline Total & 100 & 100 & 100 \\
\hline
\end{tabular}

Fonte | Dados da pesquisa

Dos licenciandos que fazem parte dos grupos EPEQII, EPEQIII e EPEQIV, $100 \%, 72,5 \%$ e 62,2\%, respectivamente, afirmaram que não, enquanto $17,5 \%$ e 34,2\%, respetivamente, responderam que sim. Para 10,0\% e 3,6\%, grupos III e IV respectivamente, não responderam segundo a Tabela 5.

Um elemento chave para poder explicar os processos e os fenômenos 261 químicos é o domínio do padrão temático específico dessa forma de comunicação científica (LEMKE, 1997). Caso não se aprenda a ensinar na formação inicial, ocorrerão consequências negativas na educação científica dos estudantes. Os fatores que os licenciandos associaram a essa resposta negativa aparecem na Tabela 6 . 


\section{Tabela 6}

Percentual de estudantes segundo a justificativa do porquê de a escola não ensinar a explicar nas aulas de Ciências Naturais

\begin{tabular}{lcccc}
\hline \multicolumn{1}{c|}{ Categorias } & EPEQll & EPEQIII & EPEQIV \\
\hline A Formação não ajuda nesse sentido & 8,6 & 10,4 & 30,6 \\
\hline $\begin{array}{l}\text { A formação está mais preocupada com passar } \\
\text { informações }\end{array}$ & 41,7 & 17,2 & 31 \\
\hline $\begin{array}{l}\text { Não existem diferenciais de como se estuda no } \\
\text { Ensino Médio e na universidade em relação a }\end{array}$ & 41,2 & 6,9 & 3,6 \\
como se constrói o conhecimento & & & \\
\hline Não se forma bem o professor & 5,7 & 24,1 & 18,0 \\
\hline Não ensina a ensinar & 0 & 20,7 & 3,6 \\
\hline Não justificam & 2,8 & 20,7 & 13,2 \\
\hline Total & 100 & 100 & 100 \\
\hline
\end{tabular}

Observa-se que as respostas fazem referência a vários fatores. Os estudantes do grupo II se referem, fundamentalmente, a problemas da formação $(41,7 \%)$ e ao fato de não haver mudança na forma de se estudar na Universidade, em relação ao Ensino Médio (41,2\%). Os do grupo III também associam suas respostas à questão da formação $(17,2 \%)$ e a não se ensinar a ensinar (20,7\%). Já no grupo IV, 30,6\% e $31 \%$ dos licenciandos se referem a problemas na formação. De maneira geral, a maioria das respostas, nos três grupos está relacionada a problemas na formação dos professores. Como exemplos, pode-se citar as respostas de dois licenciandos:

a) EIVA. $\bigcirc$ ensino universitário, assim como os instrumentos de avaliação da educação básica, ainda apresentam uma concepção conservadora de ciência que a reduz a um conjunto de informações (EIVA, 2014).

b) EllC. Alguns professores dos estágios já estão ensinando a ensinar, no entanto a formação dos professores ainda é muito técnica, ou seja, as disciplinas da área de educação se envolvem nesses conceitos, as demais são totalmente tradicionais, não se preocupam com as questões de ensino (EllC, 2014). 
Os estudos de Lira (2014), Núñez e Uehara (2012) chamam a atenção, por sua vez, para a necessidade de os professores atentarem mais para as explicações científicas no desenvolvimento de capacidades explicativas dos alunos, o que exige uma atenção na formação científica e didática dos futuros professores. Esse resultado confirma, para o caso do contexto do estudo em questão, a preocupação de vários autores concernente à necessidade de uma mudança profunda na formação inicial de professores de ciências.

\section{Considerações finais}

Aprender a ensinar ciências comporta uma formação profissional com sólida base de conhecimentos, em especial, sobre a natureza das ciências, que possibilite planejar, agir, tomar decisões em relação ao ensino das Ciências Naturais no contexto da escola do século XXI. $\bigcirc$ ensino de ciências precisa adotar, como um de seus objetivos prioritários, a prática de ajudar os alunos a aprender e a fazer ciência, ou seja, ensinar aos alunos a ciência e seus processos de produção. Nesse sentido, ensinar a explicar nas aulas de 263 Química é parte essencial do aprendizado e da compreensão dos conteúdos dessa disciplina.

O estudo, de natureza exploratória, possibilitou caracterizar o conhecimento de licenciandos em Química sobre a "explicação" como habilidade cognitivo-linguística no ensino e na aprendizagem das Ciências Naturais, assim como na produção do conhecimento científico. Os resultados mostraram fragilidades dos licenciandos em relação ao conhecimento disciplinar, que diz respeito à explicação e seu lugar nos processos de produção das Ciências Naturais, e de seu ensino, com independência do ano da formação inicial.

A maioria dos futuros professores não manifestaram um conhecimento adequado sobre o papel da explicação nas Ciências Naturais, questão necessária para se ensinar a explicar não só os fenômenos conhecidos, mas também aqueles não conhecidos pelos estudantes. De igual forma, a maioria associa a explicação científica à explicação didática na sala de aula. A explicação didática pode estar relacionada ao método da escola, que dá mais atenção às respostas prontas que à formulação de perguntas para gerar respostas baseadas em modelos explicativos. Ao expressarem o desconhecimento sobre esse conteúdo e ainda o fato de a Escola de Ensino Médio não ensinar a explicar, 
os licenciandos justificam referindo-se ao modelo de um ensino baseado na transmissão e recuperação de informações.

Por sua vez, foi constatado, no geral, um comportamento semelhante nos três grupos em todas as respostas. Isso sugere que os anos de formação, ao longo do curso, não têm influenciado no conhecimento da explicação e seu lugar nas Ciências Naturais e seu ensino no contexto escolar.

Os resultados do estudo chamam a atenção para a necessidade da formação inicial incluir, de forma explícita e planejada nos seus processos, a formação de habilidades cognitivo-linguísticas, como a explicação científica, essencial para se ensinar e aprender Ciências Naturais, como parte da educação científica na educação básica.

\section{Referências}

BARDIN, Laurence. Análise de conteúdo. Lisboa: Edições 70, 1977.

BOGDAN, Robert Charles; BIKLEN, Sari Knopp. Investigação qualitativa em educação. Uma introdução à teoria e aos métodos. Porto: Porto, 1994.

BORSESE, Aldo; ESTEBAN, Soledad. Santos. Comunicación y lenguaje en el proceso de enseñanza aprendizaje. Enseñanza de las Ciencias, Barcelona, p. 1-2, abr./jun, 2005. (Número extra).

BRASIL. Parâmetros Curriculares Nacionais: ensino médio. Ciencias naturais e suas tecnologias. Brasilia: Ministério da Educação/Secretaria de Educação Média e Tecnológica, 2002.

CARRASCOSA, Jaime; ALIS, Martínez, Joaquin Torregrosa; FURIÓ, Charles, Mas; GUISASOLA Jenaro Aranzábal. Qué hacer en la formación inicial del professorado de ciencia de la secundaria? Eureka sobre Enseñanza e Divulgación de Las Ciencias, Uvigo (Espanha), v. 5, n. 2, p. 118-133, abr./jun. 2008.

CARVALHO, Ana Maria de Pessoa. As condições de dialogo entre professores e formador para um ensino que promova a enculturação científica dos alunos. In: DALBEN, Angela; DINIZ, Julio; LEAL, Leiva (Org.). Coleção didatica e praticas de ensino. Belo Horizonte: Autêntica, 2010.

CHARAUEAU, Patrick; MAINGUENEAU, Dominique. Dicionário de análise do discurso. São Paulo: Contexto, 2004. 
CORNELL, Pedro; YERA, Pablo Miguel. El desarrollo de la habilidad explicar. La Habana: Pueblo e Educación, 2001.

DARLING-HAMMOND, Linda. El derecho de aprender: crear buenas escuelas para todos. Barcelona: Ariel, 2001.

DUSCHL, Richardl. La valoración de argumentaciones y explicaciones: promover estrategias de retroalimentación. Enseñanza de Las Ciencias, Barcelona, v. 16, n. 1, p. 3-201, jan./ mar. 1998.

DUVAL, Raymond. Semiosis y pensamiento humano. Colombia: Universidad del Valle, 1999.

EDER, Maria Laura. La explicación en la enseñanza y en las ciencias. Enseñanza de las Ciencias, Barcelona, v. 4, n. 2, p. 101-133, 2008. Disponível em: http://ddd.vab.cat/ pub/edlc/edlc_a2005nEXTRA/edlc_a2005nEXTRAp274expens.pdf. Acesso em: 3 mar. 2015.

EDER, Maria, Laura; ADÚRIZ-BRAVO, Agustin. La explicación en las ciencias naturales y en su enseñanza: aproximaciones epistemológicas y didácticas. Revista Latino Americana de Estudos Educacionais, Bogotá, v. 4, n. 2, p. 101-133, jan./mar. 2008.

265 EIVC. Questionário. Natal, 20 abr. 2014.

EIIIA. Questionário. Natal, 20 abr. 2014.

EllB. Questionário. Natal, 20 abr. 2014.

EIVB. Questionário. Natal, 20 abr. 2014.

EIV. Questionário. Natal, 20 abr. 2014.

Ell. Questionário. Natal, 20 abr. 2014.

EIVA. Questionário. Natal, 20 abr. 2014.

GILBERT, JOHN. Models in explanations. Part I. Horses for courses? International Journal of Science Education, Filadelfia (Estados Unidos), v. 20, n. 1, p. 83-97, jan. 1998.

GILBERT, JOHN. On the explanation of change in science and cognition. Science \& Education, Filadlelfia (Estados Unidos), n. 8. p. 543-557, set. 1999.

GÓMEZ, Adriana, García. Construcción de explicaciones científicas escolares. Revista Educación y Pedagogía, Antoquia (Colombia), v. 18. n. 43, p. 73-86, mayo/ago. 2006. 
GÓMEZ, Moliné. Margarita; SANMARTí, Neus Puig. Reflexiones sobre el lenguaje de la ciencia y el aprendizaje. Educación Química, Ciudad México, v. 1 1, n. 2, p. 266-273, abr./jun. 2000.

HEMPEL, Carl. La explicación científica: estúdios sobre a filosofia de la ciência. Barcelona: Paidós lbérica, 1965.

IZQUIERDO, Mercé Aymerich. Hacía una teoría de los contenidos escolares. Enseñanza de las Ciencias, Barcelona, v. 23, n. 1, p. 111 1-122, jan./abr. 2005.

IZQUIERDO, Mercé, Aymerich. Un nuevo enfoque de la enseñanza de la Química: constextualizar y modelizar. The Journal of the Argentine chemical society, Buenos Aires (Argentina), v. 92. n. 416 , p. $115-136$, agos./dez. 2004.

JIMÉNEZ, María Pilar Aleixandre. Comunicación y lenguaje en la clase de ciencias. In: JIMÉNEZ, María Pilar Aleixandre (Org.). Enseñar ciencias. Barcelona: Graó, 2003, p. 55-72.

JORBA, Jaune. La comunicación y las habilidades cognitivo-linguísticas. In: JORBA, Jaune; GÓMEZ, Isabel; ANGEL, Prats (Eds.). Hablar y escribir para aprender. Uso de la lengua en situación de enseñanza-aprendizaje desde las áreas curriculares. Barcelona: ICE Universitat Autònoma de Barcelona. Síntesis, 2000.

LEINHARDT, Gaea. Development of an Expert Explanation: An Analysis of a Sequence of Subtraction Lessons. Cognition and Instruction, Filadelfia (Estados Unidos), v. 4, n. 4, p. 225-282, jul,/set. 1987.

LEINHARDT, Gaea. Expertise in Instructional Lessons: An example from fractions'. In: GROUWS, Douglas; COONEY, Tom (Eds.). Effective mathematics teaching. New York: Lawrence Erlbaum Associates, 1988.

LEMKE, Jay. Aprender a hablar ciencia. Lenguaje, aprendizaje y valores. Barcelona: Paidós, 1997.

LIRA, Mirtes, Ribeiro. A explicação na prática discursiva pedagógica no ensino de ciências naturais. Jundaí: Paco, 2014.

MARCELO, Carlos García. Formalidade e informalidade no processo de aprender a ensinar. In: PUENTE, Roberto Valdes; AQUINO, Orlando Fernández; LONGAREZI, Andrea Maturamo (Org.). Ensino médio: estado atual, políticas e formação de professores. Uberlândia: EDUFU. 2012. 
Conhecimento profissional para ensinar a explicar processos e fenômenos nas aulas de Química

MINAYO, Maria. Cecilia. de Souza. O desafio do conhecimento: pesquisa qualitativa em saúde. 12. ed. São Paulo: Hucitec, 2010.

MORTIMER, Eduardo. Fleury; VIEIRA. Ana Clara. Letramento científico em aulas de química para o ensino médio: dialogo entre linguagem científica e linguagem cotidiano. In: DALBEN, Angela; DINIZ, Julio; LEAL, Leiva (Org.). Coleção didática e práticas de ensino Belo Horizonte: Autêntica, 2010.

NÚÑ̃Z, Isauro Beltrán. Vygotsky, Leontiev, Galperin. Formação de conceitos e princípios didáticos. Brasília: Líber, 2009.

NÚÑEZ, Isauro Beltrán; RAMALHO, Betânia Leite. As habilidades gerais: reconhecer, interpretar, tomar decisões, calcular, aplicar e explicar na prova do ENEM 2009. In: NUÑEZ, Isauro Beltran; RAMALHO, Betania Leite (Org.). Aprendendo com o ENEM: reflexões para melhor se pensar o ensino e a aprendizagem das ciências naturais e da matemática. Brasília: Liber, 2011.

NÚÑEZ, Isauro Beltrán; UEHARA, Fabia Maria Gómes. A explicação científica e o conhecimento profissional na formação de professores de Química. In: ENCONTRO NACIONAL DE PESQUISAS E PRATICAS EM EDUCAÇÃO. 1; 2012, Natal. Anais... Natal: Universidade Federal do Rio Grande do Norte, 2012.

NÚÑEZ, Isauro Beltrán; RAMALHO, Betania Leite. Desarrollo de una unidad didáctica para el estudio de los procesos de oxidación-reducción en el pre-universitario: contribuciones de la teoría de P. Ya. Galperin. In: SILVA, Marcia Gorette Lima da; MOHR, Adriana; ARAUJO, Magnolia Fernandes Florencio de. Temas de ensino e formação de professores de ciências. Natal: EDUFRN, 2012.

OGBORN, Jon. Formas de explicar. Madrid: Santillana/Aula XXI, 1998.

POZO, Juan Ignácio; CRESPO, Miguel Angel Garcia. A aprendizagem e o ensino de ciências: do conhecimento cotidiano ao conhecimento científico. São Paulo: Artmed, 2009.

RAMALHO, Betania Leite; NÚÑEZ, Isauro Beltrán; GAUTHIER, Clemont. Formar o profesor, profesionalizar o ensino. Desafíos e perspectivas. Porto Alegre: Sulinas, 2004.

SANMARTí, Neús Puig. El lenguaje y la experimentación, en las clases de Química. Educación abierta: aspectos didácticos de Física y Química. Zaragoza (Espanha), n. 163, p. 183-202, jul./set. 2003. 
SANMARTí, Neús Puig. Hablar, ler y escribir para aprender ciência. In: ALEIXANDRE, Maria Del Pilar Jimenez (Org.). La competência em comunicación linguística em las áreas del currículo. Madrid: Ministerio de Educación y Cultura, 2007.

TARDIF, Maurice. Saberes docentes e prática profissional. Petrópolis: Vozes, 2002.

TOULMIN, Stephen. La comprensión humana. El uso colectivo y la evolución de conceptos. Madrid: Alianza, 1977.

Prof. Dr. Isauro Beltrán Núñez

Universidade Federal do Rio Grande do Norte Departamento de Práticas Educacionais e Currículo

Programa de Pós-Graduação em Educação Grupo de Pesquisa Aprendizagem, Formação e Profissionalização Docente E-mail | isaurobeltrán@yahoo.com.br

Profa. Dra. Betania Leite Ramalho Universidade Federal do Rio Grande do Norte Departamento de Práticas Educacionais e Currículo

Programa de Pós-Graduação em Educação

E-mail | betania.leite@uol.com.br

RRecebido 4 maio 2015

Aceito 7 jun. 2015 